\title{
Editorial
}

\section{La Institución Universitaria Politécnico Grancolombiano en sus treinta años}

\section{Educación técnica y tecnológica}

En la década de los setenta en Colombia existían muchos profesionales tradicionales, como abogados, economistas, médicos e ingenieros, con un alto índice de desempleo. Se decía que había hasta médicos manejando taxi. Y, al mismo tiempo, el país carecía de los técnicos y tecnólogos que necesitaba para su desarrollo académico y social. Por esta razón el Gobierno Nacional dictó el Decreto Ley 80 de 1980, con el propósito de promover la educación técnica y tecnológica, es decir la formación de expertos más prácticos y eficientes requeridos por parte de las empresas públicas y privadas.

Fue con base en esta legislación que en 1980 se creó la Fundación Politécnico Grancolombiano, inicialmente como una institución exclusivamente tecnológica, que desde entonces, ha sido una de las más prestigiosas promotoras y defensoras de este tipo de educación, sin perjuicio de transformarse años más tarde en Institución Universitaria. La operación académica de la Fundación comenzó en el año siguiente, en 1981.

\section{Los fundadores}

El Politécnico Grancolombiano fue fundado por varias de las empresas del Grupo Grancolombiano y el Banco de Colombia y sus correspondientes directivos, bajo el liderazgo de Jaime Michelsen Uribe y su señora María Cristina Niño de Michelsen, dentro de un gran conjunto de obras e instituciones de beneficio social, que ellos crearon o promovieron alrededor de la organización. Ellos tenían el propósito de ir solucionando poco a poco las necesidades básicas de los colaboradores del grupo empresarial y de muchas otras personas-educación, salud, vivienda, cultura, entre otras- y por ello crearon y apoyaron diversas obras, como universidades, colegios, guarderías, e instituciones de salud, culturales e investigativas.

Aunque el Grupo Grancolombiano fue injustamente destruido a comienzos de los años 1980, varias de esas instituciones de beneficio social sobrevivieron autónomamente, como es el caso del Politécnico Grancolombiano. 


\section{Las carreras iniciales}

Como correspondía a una institución de carácter tecnológico, las primeras carreras del Politécnico Grancolombiano fueron tecnológicas, en las disciplinas de Finanzas, Banca, Seguros, Empresas Agropecuarias, Mercadeo y Publicidad, Sistemas, y Costos y Auditoría. También tuvo varias especializaciones tecnológicas en el nivel de posgrado, en algunas de las mismas disciplinas. De esta forma la institución buscaba proveer los recursos humanos, que con urgencia necesitaba la economía colombiana y organizaciones como el Grupo Grancolombiano, uno de los primeros grandes grupos empresariales del país.

\section{Institución Universitaria}

El Politécnico Grancolombiano tuvo un gran desarrollo como institución tecnológica y desde su fundación ha sido una de las instituciones de educación superior más representativas en este campo.

En 1992 se expidió en Colombia una nueva reforma legislativa de la educación superior, por medio de la Ley 30 de 1992, y con base en ella el Politécnico Grancolombiano se transformó en "institución universitaria". Esto le permitió, sin perjuicio de conservar la mayoría de sus programas tecnológicos (de tres años de duración), poco a poco ir estableciendo un portafolio de programas profesionales (de cuatro a cinco años de duración) y de posgrado, por ahora en el nivel de especialización, en diversos campos del conocimiento. En la actualidad, todos los programas académicos de la institución se encuentran agrupados en las siguientes cuatro facultades:

1. Facultad de Ciencias Administrativas, Económicas y Contables

2. Facultad de Ingeniería y Ciencias Básicas
3. Facultad de Mercadeo, Comunicación y Artes

4. Facultad de Ciencias Sociales.

\section{Contra la cátedra magistral}

La Institución Universitaria Politécnico Grancolombiano (IUPG) siempre ha luchado contra los vicios de la educación tradicional, como el síndrome de "profesores que hablan enfrente de estudiantes que duermen", y en general, la pasividad académica de los estudiantes.

Las estrategias de la institución para procurar un modelo educativo más autónomo, proactivo, deliberante e investigativo por parte del estudiante se resumen en el concepto de universidad universal.

\section{La universidad universal}

La palabra universidad proviene del sustantivo universo, pero, a nuestro juicio, las universidades desde su fundación aproximadamente en el siglo XII (universidades de Bolonia, Oxford y Salamanca), no han correspondido suficientemente a ese concepto de universalidad. Por el contrario, en general, han sido relativamente elitistas, con base en criterios económicos o académicos.

Para nosotros la universidad universal se caracteriza por:

Ser inclusiva, no exclusiva, es decir, por brindarle oportunidades al mayor número posible de personas, pero sin regalarles nada en lo académico.

Educar integralmente, no solo para las disciplinas o profesiones, sino para la construcción de proyectos de vida felices y exitosos.

Participar en toda la cadena de formación, mediante programas académicos presenciales y a distancia o virtuales, por 
ciclos propedéuticos, tanto formales -técnicos, tecnológicos, profesionales y posgrados-como no formales - articulación entre secundaria y universidad, técnicos laborales, formación empresarial a la medida, y educación continuada en general-.

Preparar para actuar no solo en un país o en un ámbito en particular, sino en la comunidad internacional en proceso de globalización cultural.

Utilizar las tecnologías de la información y las comunicaciones (TIC) para llevar la universidad universal a todas partes, y capacitar para el uso de las mismas TIC.

Contribuir a la solución de los problemas universales, como la pobreza y la destrucción del medio ambiente, y crear valores agregados, por medio de las tres funciones de la universidad: docencia, investigación y proyección social o extensión.

Formar en valores universales, como el espíritu de bondad y de amor al prójimo.

\section{Calidad académica - acreditación}

En este derrotero de la universidad universal, la IUPG tiene una preocupación fundamental por la calidad académica. Por esta razón, ya todos nuestros programas académicos formales cuentan con sus Registros Calificados (acreditación básica) ante el Ministerio de Educación Nacional (MEN), y están en proceso de autoevaluación con miras a la Acreditación de Alta Calidad por parte del mismo MEN, previo concepto del Consejo Nacional de Acreditación (CNA).

Ya dos de nuestros más importantes programas, Mercadeo y Publicidad e Ingeniería de Sistemas, ambos con ciclos tecnológico y profesional, tienen la Acreditación de Alta Calidad.

\section{Internacionalización para la globalización}

La IUPG forma parte de la red American University System (antes Whitney International University System), que por ahora reúne cerca de 60.000 estudiantes en universidades o instituciones profesionales de gran prestigio, en Argentina, Brasil, Chile, Colombia, Estados Unidos y Panamá, y se seguirá extendiendo por toda Latinoamérica.

Por medio de esta red y de la Red Latinoamericana de Cooperación Universitaria (RLCU), de la cual también es miembro, la IUPG ha logrado construir un importante conjunto de oportunidades de desarrollo académico en el exterior para nuestros estudiantes y profesores. En el primer semestre de 2010 tuvimos 195 estudiantes en 34 países, realizando experiencias académicas en el exterior, y también varios profesores, desarrollando incluso doctorados en prestigiosas instituciones.

\section{Universidad inclusiva}

La IUPG admite a todos los estudiantes que cumplan con los requisitos básicos, al igual que las dos universidades más grandes de Latinoamérica, la UNAM de México (700.000 estudiantes) y la UBA de Argentina (300.000 estudiantes), y les presta diversas ayudas para la superación de sus limitaciones académicas.

Por medio de su educación virtual la IUPG ofrece programas académicos en Colombia a un costo módico.

\section{Educación virtual 0 a distancia}

La IUPG tiene un novedoso modelo de educación virtual que combina los siguientes elementos: 
- Campus virtual en internet

- Estudios para transmisión vía satélite

- Centros Locales de Aprendizaje distribuidos en distintas ciudades

- Tecnología satelital para transmitir contenidos y teleconferencias

- Plataformas de diseño y administración curricular: Moodle y Epic

- Currículos por logros y competencias

- Asistencia tutorial permanente.

\section{Educación integral}

La IUPG en su Decanatura del Medio Universitario ofrece a la comunidad uni- versitaria asistencia académica y psicológica, así como un amplio programa de actividades culturales y deportivas. En general, todo el personal académico y administrativo de la institución está imbuido de la misión de brindar al estudiante atención personalizada.

\section{Cadena de formación}

La IUPG participa en casi toda la cadena de formación, así:

\begin{tabular}{l|ll|l|l} 
Po formal & Técnica laboral & & \\
Virtual & $\begin{array}{lll}\text { Formal } \\
\text { universitaria }\end{array}$ & $\begin{array}{l}\text { Técnica } \\
\text { Tecnológica }\end{array}$ & Continuada & Abierta \\
& Profesional & A la medida
\end{tabular}

\section{Técnicas de información y comunicación}

El uso de las TIC es muy intensivo en la IUPG a través de su intranet, de internet, de su campus virtual, de su Centro de Medios Audiovisuales, de las redes internacionales de alta velocidad (Rumbo, Renata, Clara, internet 2.0, Geant), para lo cual la comunidad universitaria cuenta con un gran número de computadores.

Todas las asignaturas de los programas académicos tanto presenciales como virtuales están implantadas en el Moodle (software libre de educación a distancia) para facilitar la interactividad entre estudiante y profesor.
Recientemente la institución adquirió el Power Campus, que es uno de los más avanzados sistemas de información integrados para universidades con todos los componentes administrativos y académicos.

\section{Fundación Compuclub}

Esta filial de la IUPG ha sido por más de 25 años uno de los más grandes capacitadores en sistemas de información de Colombia y, por tanto, un importante aliado de varias marcas internacionales de software, como Microsoft, Novell, SAP, FOX-IT, Oracle, entre otras.

Compuclub les presta capacitación para el uso de sistemas a los estudiantes de la institución. 


\section{Investigación}

El modelo de investigación de la IUPG está dividido en dos ramas, a saber:

Investigación formativa, que promueve los proyectos de investigación surgidos del aula de clase con la participación de estudiantes y profesores, por medio de semilleros de investigación, células tecnológicas y la articulación con proyectos de investigación aplicada.

Investigación aplicada, cuyos proyectos buscan solucionar problemas del mundo empresarial real.

\section{Proyección social}

La IUPG gestiona todo un conjunto de proyectos que buscan llevar la academia a ese mundo social, económico y empresarial real, como prácticas empresariales, consultorías, ayudas a instituciones de beneficio social, becas por necesidad y por rendimiento académico, becas para minorías raciales y étnicas, programas de formación empresarial abiertos o a la medida, ayuda a comunidades vecinas, desarrollo de un modelo de gestión ambiental, entre otros.

\section{Profesorado}

En la actualidad la IUPG tiene 124 profesores de planta, de tiempo completo, a término indefinido, sin contar 17 directores de departamentos y áreas académicos, $y$ 355 profesores por horas-cátedra. De esta forma se combinan con éxito la experiencia profesional y la dedicación exclusiva a la educación. En conjunto, suman 479 docentes, cuidadosamente seleccionados por comités de selección, que están agrupados en los siguientes 16 departamentos académicos:

\section{Administración}

2. Economía y Finanzas

3. Turismo

4. Internacional

5. Contabilidad

6. Diseño y Artes

7. Comunicación

8. Medios Audiovisuales

9. Mercadeo y Publicidad

10. Industrial

11. Sistemas y Telecomunicaciones

12. Ciencias Básicas

13. Psicología

14. Derecho y Ciencia Política

15. Humanidades

16. Idiomas

\section{Población estudiantil y deserción}

En la actualidad la IUPG tiene aproximadamente 9.000 estudiantes presenciales, 4.500 virtuales y 1.000 de educación continuada. Desde el año 2008 a la fecha, la institución ha logrado reducir en forma significativa su deserción estudiantil de 18 a 10\%, manteniéndola por debajo de esta cifra en los últimos semestres, por lo cual su programa antideserción, en concurso con otras instituciones de educación superior, se ganó en 2009, un importante apoyo económico por parte del Ministerio de Educación Nacional.

\section{Valores universales}

Los valores universales son un elemento fundamental de la universidad universal. La IUPG no es una institución confesional, no pertenece a ninguna religión ni a ninguna ideología en particular, precisamente porque las respeta a todas. Sin embargo, sí profesa un valor universal, 
el espíritu de bondad y amor al prójimo, incluso los ateos, quienes para el efecto que para no darle solamente una con- están sometidos a los jueces más implanotación religiosa, pero sin perjuicio de cables, que son la conciencia y el corazón ella, hemos preferido denominar sentido de cada persona. de solidaridad, equidad, generosidad y amabilidad. Este principio no riñe con Pablo Michelsen Niño ninguna religión o ideología, y debe ser Rector cumplido por todos los seres humanos,

Bogotá, julio de 2010 